\title{
The School, a Viable Educational Site for Interdisciplinary Health Promotion
}

Article in Education for Health · December 2004

DOI: $10.1080 / 13576280400002460 \cdot$ Source: PubMed

CITATIONS

21

3 authors:

(2) Firdouza Waggie

University of the Western Cape

23 PUBLICATIONS 73 CITATIONS

SEE PROFILE

Pradeep Brijlal

University of the Western Cape

19 PUBLICATIONS 302 CITATIONS

SEE PROFILE

Some of the authors of this publication are also working on these related projects:

student (oral hygiene) stress in the dental environment View project 


\title{
The School, a Viable Educational Site for Interdisciplinary Health Promotion
}

\author{
FIRDOUZA WAGGIE ${ }^{1}$, NATALIE GORDON ${ }^{2} \&$ \\ PRISCILLA BRIJLAL ${ }^{2}$
}

${ }^{1}$ Faculty of Community and Health Sciences, and ${ }^{2}$ Faculty of Dentistry, University of the Western Cape, Bellville, Republic of South Africa

\begin{abstract}
Background: An interdisciplinary health promotion module, using the community-based teaching approach, is offered by the University of the Western Cape $(U W C)$. Schools in Delft, a poor socio-economic area with high unemployment, crime and a range of social problems, are used as the teaching site.
\end{abstract}

Aim: To assess the status of the health promotion initiatives in schools where students were placed.

Method: A self-administered structured questionnaire for teachers and principals. Variables included were demographic data, views of health promotion, health promotion activities at the school, barriers and opportunities to implement health promotion activities.

Results: A response rate of $68.75 \%(\mathrm{n}=55)$ for teachers and $100 \%(\mathrm{n}=4)$ for principals was obtained. Most (87\%) teachers felt that health promotion has a place within the curriculum. They reportedly focused on topics related to health within the school curriculum. Partners, such as public health nurses, university students, and a pharmaceutical company, offer additional health promotion initiatives. These include general health checks, HIV/AIDS information, adolescent health and dental health. Barriers to initiate and sustain programmes include lack of resources, insufficient staff training, lack of commitment by both teaching staff and the community, insufficient time, the heavy workload of teachers, and communication problems as a result of language barriers. Only $36 \%$ of teachers felt the school environment was conducive to learning.

Conclusion: Health promotion initiatives in the schools concerned are uncoordinated, erratic, based on the resources that the school has access to at a given time and the demands of the curriculum.

Author for correspondence: Ms. Firdouza Waggie, Foundational Learning and Teaching Specialist, Faculty of Community and Health Sciences, University of the Western Cape, Private Bag X17, Bellville 7535, Republic of South Africa. Tel: +27 219593627. Fax: + 27219592755. E-mail: fwaggie@uwc.ac.za 
KEYWORDS School health promotion, community-based education, health promoting schools, opportunities/barriers for health, intersectoral collaboration, poor socio-economic environments.

\section{Introduction}

Tertiary institutions are responsible for producing health professionals who can respond effectively and competently to the challenge of improving the health status of South Africans, thereby contributing to building an equitable and dynamic society. Increasingly, community-based and interdisciplinary education are integrated into curricula in the health sciences. It is expected that early and extensive contact with the community will better prepare students to deal with challenges they encounter in practising their profession. Furthermore, it enhances collaboration for an intersectoral approach to address health.

Many South Africans were seriously disadvantaged through grossly inequitable access to health services and health-related information (Lalloo, 1995). The School Register of Needs Survey 1996 (Visser, 1998) identified major problems in the social and physical environments in schools. Learners attended schools with classroom shortages (49\%), no water within walking distance $(20 \%)$, no electricity (45\%), no toilet facilities $(55 \%)$ and poor school buildings (17\%) (Visser, 1998). Reports of inadequate nutrition, alcohol and drug abuse, deficiencies in early childhood development, child protection and social welfare, risky behaviours such as violence, sexual interaction, roadrelated accidents and smoking, further highlight the situation in South African schools (Swart \& Reddy, 1999). These factors create an unhealthy environment for the school community and hamper learning. This supports global and local initiatives to develop schools as a setting for health promotion (De Jong, 2000).

The ministries of Health, Education and Welfare adopted the healthpromoting school concept in 1994. The principles of an integrated, holistic and co-ordinated approach, quality assurance, capacity-building, utilization of existing resources, ownership and sustainability, equity and redress were proposed as a guide to develop health promoting schools/sites in South Africa (Health Promotion-Task Team, 2000).

It is against this background that the Faculties of Dentistry and Community Health Sciences at the University of the Western Cape (UWC) developed a community-based interdisciplinary health promotion module for students in the foundation year(s). The purpose was to create a mutually supportive relationship where the school becomes a site of learning for students and benefits through the expertise and resources provided. After two years it became evident that the purpose of this project was not being met. There was a lack of visible and coordinated health promotion efforts. Initiatives appeared to be isolated and to some extent limited to student projects carried out in one semester of the academic year. 


\section{Background}

The schools involved are located in a poor socio-economic area with high levels of unemployment, crime and a range of social problems (Table 1).

In consultation with teachers and facilitators, health promotion projects were identified and developed using the health promoting schools conceptual framework and the project planning cycle (Coulson et al., 1998) as a guide. It was anticipated that projects chosen would be sustained by the school community.

In November 2002, this study was initiated as part of the evaluation process of the health promotion module. This paper will discuss the challenges faced by educators trying to sustain health promotion activities within a poor socioeconomic environment.

\section{Aim}

This study assesses the status of the health promotion initiatives in the Delft schools where UWC students were placed (Table 2).

\section{Objectives}

The objectives were to determine:

1 Health promotion activities in the respective schools.

2 Opportunities and barriers to develop and sustain health promotion activities in the schools.

3 The knowledge and attitude of teachers and principals toward school health promotion.

Table 1. School demographic data

\begin{tabular}{|c|c|c|c|c|c|c|c|}
\hline School & $\begin{array}{l}\text { Primary/ } \\
\text { Secondary }\end{array}$ & $\begin{array}{l}\text { Estab- } \\
\text { lished }\end{array}$ & $\begin{array}{l}\text { Health } \\
\text { Promot- } \\
\text { ing } \\
\text { School }\end{array}$ & $\begin{array}{c}\text { Total } \\
\text { No. of } \\
\text { Learners }\end{array}$ & $\begin{array}{l}\text { No. of } \\
\text { Educa- } \\
\text { tors }\end{array}$ & $\begin{array}{l}\text { Teaching } \\
\text { Medium }\end{array}$ & $\begin{array}{c}\text { Dominant } \\
\text { language } \\
\text { spoken }\end{array}$ \\
\hline 1 & Primary & 1998 & Yes & 1200 & 37 & English & Xhosa \\
\hline 2 & Primary & 1990 & No & 1200 & 35 & Afrikaans & $\begin{array}{l}\text { English \& } \\
\text { Afrikaans }\end{array}$ \\
\hline 3 & Primary & 1994 & Yes & 1268 & 34 & English & Afrikaans \\
\hline 4 & Secondary & 1992 & No & 935 & 30 & English & Afrikaans \\
\hline
\end{tabular}


Table 2. Student allocation

\begin{tabular}{lcccc}
\hline $\begin{array}{l}\text { Number of } \\
\text { schools }\end{array}$ & $\begin{array}{c}\text { Student numbers } \\
\text { (UWC) }\end{array}$ & $\begin{array}{c}\text { Weeks spent } \\
\text { at each school } \\
\text { (2hrs per } \\
\text { week) }\end{array}$ & $\begin{array}{c}\text { Number of } \\
\text { student } \\
\text { groups }\end{array}$ & $\begin{array}{c}\text { Mean number } \\
\text { of students } \\
\text { per school }\end{array}$ \\
\hline 4 & 249 & $16^{*}$ & 8 & 31 \\
\hline
\end{tabular}

* Two rotations: one group per school per 8 weeks

\section{Method}

Three primary and one secondary school were included in this study. Data was gathered by means of a self-administered structured questionnaire* for teachers $(n=80)$ and principals $(n=4)$. Twenty questionnaires were randomly distributed at each school and were completed anonymously. Participation was voluntary. The variables measured included demographic data of the school, teachers'/principals' views of health promotion, barriers and opportunities to implement health promotion.

\section{Results}

\section{Demographic Information}

The response rate was $68.75 \%(n=55)$ for teachers and $100 \%(n=4)$ for principals. There was a governing body at each school tasked with the responsibility of ensuring that the school functioned effectively as a unit. Parent/teacher meetings were held quarterly or semi-annually. All schools had electricity and running water, but the general infrastructure, such as boundary fences, library resources and school buildings, were neglected. A number of teachers $(36 \%)$ ) felt the school environment was conducive to learning, 38\% felt it was not and $25 \%$ did not respond.

\section{Respondents' Views on Health Promotion}

Teachers perceived health promotion as healthy, clean and safe environments and holistic care of individuals and communities. Most (87\%) teachers felt that health promotion had a place within the curriculum. Amongst the views expressed were the importance of engendering in learners the value of a healthy lifestyle and a healthy mind, raising awareness about health issues within schools and the community, and the necessity to address issues such as 
HIV/AIDS. All the principals felt that schools should become part of the health promoting schools initiative.

\section{Health Promotion Initiatives}

Teachers' activities focused primarily on health topics related to the formal school curriculum. Other initiatives included health checks by the school health nurse, HIV/AIDS information by public health nurses, dental health and HIV/ AIDS awareness by teachers, and workshops about adolescent health for girls by a pharmaceutical company. The initiatives by the UWC students included road and home safety, sexuality and gender relations, HIV/AIDS, body hygiene, dental hygiene, nutrition, tuberculosis, substance abuse, improving the school environment through painting classrooms and cleaning the school grounds. Their focus was to promote positive and informed behaviour practices as well as to create healthy and aesthetically acceptable environments conducive for learning, living and playing.

Many activities were not sustained by teachers or principals and occurred sporadically. Health promotion activities were done by $51 \%$ of teachers. Primarily foundation teachers (29\%) were involved in sustaining these activities. Half $(50 \%)$ of the teachers reported to the principals and other teachers about health promotion activities.

\section{Barriers and Opportunities}

Table 3 illustrates the barriers and limitations to health promotion programmes as identified by the teachers and principals.

The opportunities identified were schools having access to university students for half of the academic year although limited to public health nurses and a pharmaceutical company. Principals and teachers felt that schools could sustain programmes if the barriers are addressed.

\section{Discussion}

\section{Demographic Information}

The lack of notable differences between the health promoting and other schools shows the discrepancy between adopting policies and the good intentions thereof and the reality prevailing in schools. Poor communities, where there is the greatest need, may have the least benefit of progressive policies if structures are not put into place to support these policies. According to Hirschowitz et al. (1995) "an unstable and poor socio-economic area generally has the highest rates of crime, ill-health, unemployment, poverty, famine and low education levels". Within this context, the risks that these children are exposed to highlight the need to invest in schools and thereby assist parents and children to see opportunities outside of their negative environment. 
Table 3. Barriers and limitations as identified by teachers and principals

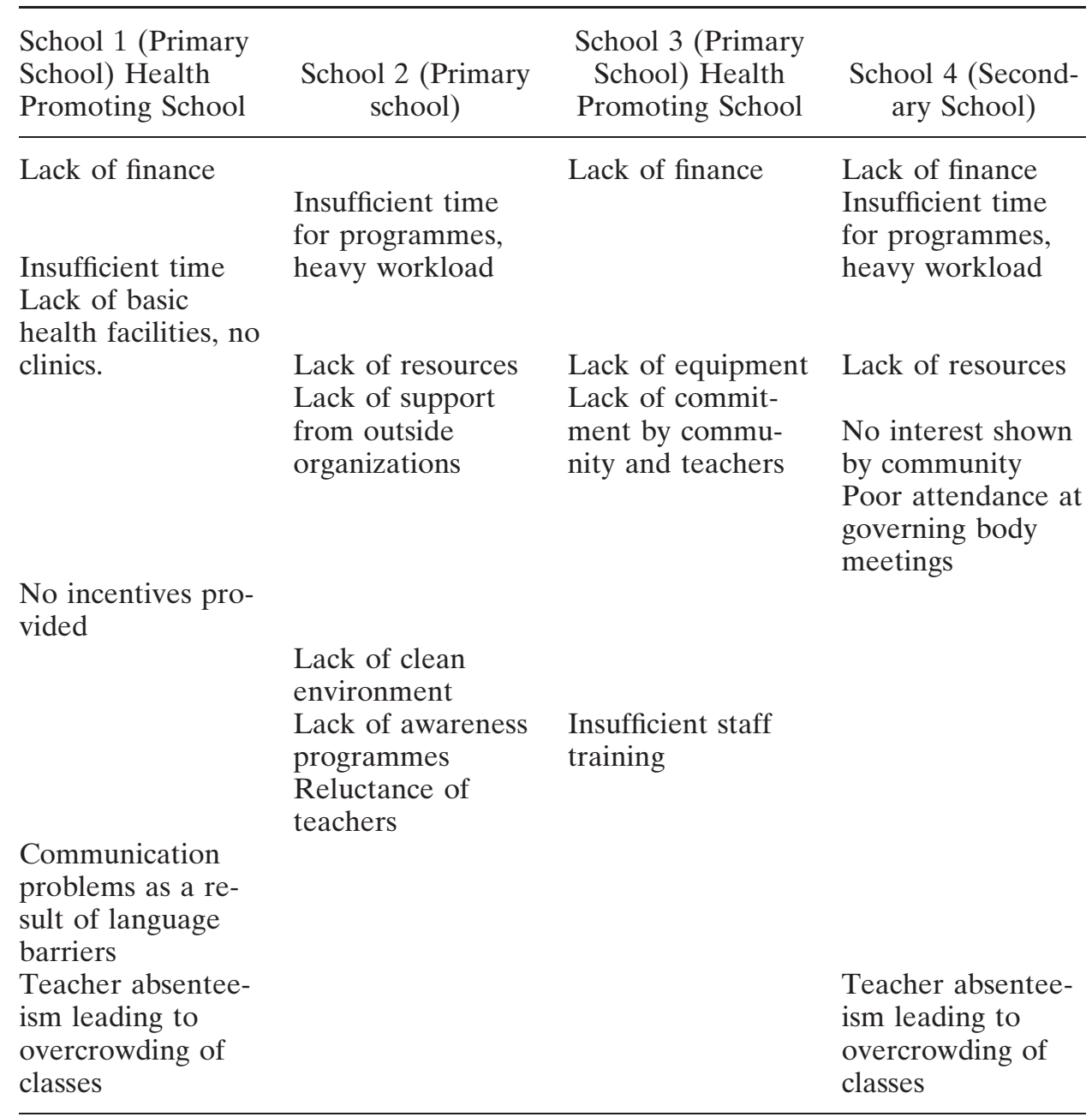

\section{Health Promotion Initiatives}

The initiatives appear to fall into distinct categories, those done by teachers, outside parties and UWC students, resulting in vertical programmes seemingly done in isolation.

Rather than motivate students to sustain programmes, teachers may have encouraged students to do a variety of projects that exposed their learners to a range of activities. This may indicate that the purpose of the project was interpreted differently by educators at schools and the university.

The limited intersectoral collaboration at all the schools clearly shows that the school communities have little support to meet the principles, as set out in the South African guidelines for health promoting schools. Even where other 
sectors are involved, interventions appear to be in the form of vertical programmes. Seager (1990) proposed that in the past, educationalists tended to resist the inclusion of extensive health education in school curricula, arguing that it is less important than the academic subjects. The fact that educationalists in this sample felt that health promotion should be included in the curriculum shows that this view may be changing. Foundation teachers may become more active in health promotion activities, as health education aspects are included in their curriculum.

Many teachers do not initiate or sustain health promotion activities. This should be viewed against the enormous challenges they face to fulfill their primary function as educators. Some may see health promotion initiatives as time lost from their teaching responsibilities. Considering that only $36 \%$ of the teachers felt that the school is conducive to learning, they may see the need for a healthier school environment and community. However, it may not be the criteria by which they are assessed as educators. They also appear to see the health promoting schools framework as a series of activities within their responsibility. This may point to a lack of understanding of teachers and health professionals of a "health promoting school being characterized as a school constantly strengthening its capacity as a healthy setting for living, learning and working" (WHO, 1997). Furthermore, they may feel burdened by what they see as the responsibilities of the departments of health and welfare.

According to Kickbusch and Jones (1998), organizations can assist schools become health-promoting by helping them to build an appropriate infrastructure, enhance efforts that allow the school community to create conditions conducive to health, implement integrated efforts to reduce important health problems and monitor the implementation and effectiveness thereof. A definite structure with multiple partners to promote health in the school environment is inherent in this view, rather than the loose uncoordinated efforts currently seen. This will address the barriers identified and give meaning to the terms intersectoral collaboration and community participation.

\section{Barriers and Opportunities}

The WHO Expert Committee (1999) identified barriers to the development of school health programmes as inadequate vision to the strategic planning, inadequate understanding and acceptance of programmes; lack of responsibility and accountability inadequate collaboration and coordination among persons addressing health in schools and lack of programme infrastructure. This study identifies similar barriers. Despite these, research has shown that in both developing and developed countries, school health programmes can simultaneously reduce common health problems, increase the efficiency of the education system and advance public health, education and social and economic development in each nation (WHO Expert Committee, 1999). 
This raises the question of the process involved in schools joining the health promoting schools initiative, as well as the monitoring of the health promotion module in respect of its purpose. The health promotion activities do not appear to be organized around creating a healthy setting for living, learning and working for students or staff. Health promotion efforts appear to be planned around the resources available at the time, such as university student programmes, the services of a pharmaceutical company, demands of the curriculum for the respective grades in terms of health topics, and issues that individual teachers felt important for their students. These factors may contribute to the general lack of sustainability of initiatives. Basic infrastructure to enhance learning is not in place. There appears to be little support for teachers and learners because of the type of societal problems reflected in the schools. However, all schools appear to subscribe to the principle of utilization of existing resources.

Language as a barrier reflects South Africa as a multilingual society, thus creating a need for innovative, creative learning and teaching strategies. Promoting multilingualism in the school environment may create a platform to address cultural diversity and thereby contribute to the well-being of the school community. In the absence of this, language may become a divisive factor in the school environment.

The different views of principals and teachers regarding barriers may relate to their differing roles. The principals, as managers, identified barriers affecting the school operation, whereas the teachers identified barriers related to their daily functioning. This may also indicate that the principals may not be fully informed of the problems teachers face, or may only be aware of problems of those teachers who report on their health promotion activities. The absenteeism reported may indicate that the teachers not only find the school to be a negative environment for learning and for teaching as well. The principals may view the attitude displayed as a lack of commitment.

\section{Review of the Health Promotion Module}

The presentation, initiation and monitoring of the health promotion module need to be reviewed with clarification of the roles and responsibilities of all parties. It may be more realistic to focus on health promotion themes that would build and sustain programmes in consultation with all stakeholders within individual schools. As a stakeholder, the broader university community could make a greater contribution by sharing its expertise through training programmes for the school community. This would involve looking at the school programme holistically rather than the current involvement only during one semester of the academic year without taking responsibility for effecting change within the school environment.

The findings of this study highlight the importance of thorough research of the educational site when using the community based learning strategy. Appropriate programmes can thus be developed that will avoid unrealistic or 
incorrect expectations, maximizing the health and learning benefits of both the school community and the tertiary institution.

\section{Conclusion}

The schools provide a valuable site for community-based education. Although most educators practise health promotion positively, numerous barriers hinder health promotion sustainability. The success of the school as a viable site for interdisciplinary health promotion education requires not only commitment but also thorough planning and continuous monitoring.

\section{Acknowledgements}

The following lecturers facilitated the interdisciplinary health promotion module: Sharmilah Jaffer, Liezl Cornelissen, Gertrude Leukes, Patricia Struthers, Gerard Fielies Luke Arunachullum, Rughshana Cader.

\section{References}

Coulson, N. (1999). Health Promotion. In Crisp \& Nicolas (Eds), South African Health Review, Durban: Health Systems Trust, 289-300.

Coulson, N., Goldstein, S. \& NTUli, A. (1998). Project planning and evaluation. In Promoting health in South Africa: An action manual. Heinemann: Sandton, pp. $158-$ 171.

DE Jong, T. A. (2000). The role of the school psychologist in developing a healthpromoting school: Some lessons from the South African context, School Psychology International, 21, 339.

Health Promotion-Task Team. (2000). National guidelines for the development of health promoting schools/sites in South Africa. Department of Health, pp. 16-17.

HiRsCHOwITZ, R. \& ORKIN, M. (1995). Learning problems and remedial education, In The National Household Survey of Health Inequalities in South Africa, Washington: The Community Agency for Social Enquiry (CASE) for The Henry J. Kaiser Family Foundation, pp. 45-46.

KICKBUSCH, I. \& JONES, J.T. (1998). Health-promoting schools, UNESCO International Science, Technology \& Environmental Education Newsletter, 23, 4.

LALlOO, R. (1995). Equity in health revisited, Journal of Comprehensive Health, 6, $199-201$.

SEAGER, J.R. (1990). The need for health education in South African schools, Journal of Comprehensive Health, 1, 50-53.

SWART, D. \& REDDY, P. (1999). Establishing networks for health promoting schools in South Africa, Journal of School Health, 69, 47-50. 
312 F. Waggie et al.

VISSER, M. (1998). School Register of Needs Survey 1996. Pretoria: Human Sciences Research Council.

World Health Organisation (WHO) Expert Committee On COMPREhEnsive SCHOOLS (1997). Health education and promotion. WHO Technical report series 870. Geneva: WHO.

World Health Organisation (WHO) ExPERT CommitTeE. (1999). Improving school health programmes: barriers and strategies. WHO/ HPR/HEP/96.2. Geneva: WHO. 